www.jmscr.igmpublication.org

Index Copernicus Value: 79.54

ISSN (e)-2347-176x ISSN (p) 2455-0450

crossrefDOI: https://dx.doi.org/10.18535/jmscr/v7i1.142

\title{
Prevalence of androgen receptor positivity in triple negative breast cancers: clinico-pathological significance
}

\author{
Authors \\ Debahuti Mohapatra, Debasmita Das*, Pranita Mohanty, Rajashree Tripathy \\ Department of Pathology, IMS and SUM hospital, Siksha "O" Anusandhan University, \\ K8, Kalinganagar, Bhubaneswar-751003, Odisha, India \\ *Corresponding Author \\ Dr Debasmita Das \\ P.G Student, Dept. of pathology, IMS \& SUM Hospital \\ Email: dasdiya64@gmail.com, Cell: 9620814629
}

\begin{abstract}
A unique subgroup of breast cancer, the Triple negative breast carcinoma (TNBC) is on rising trend. TNBC occurrence is around 15\%-20\% of all breast cancers. They are defined by absence of target therapy and prognostically worse as far as size, morphology, grading and staging are concerned. Thus, recent advent of androgen receptor (AR) sensitive target in some of the TNBC, which though are prognostically bad but has initiated target therapy successfully but still is under study. It is a sign of optimism for the oncologist for the treatment of incurable types of TNBCs. A study was done at IMS and SUM hospital, Bhubaneswar on 110 cases of breast carcinoma, among which 24 cases were TNBC. These included high grade infiltrating duct carcinoma (IDC-NST), metaplastic carcinomas, medullary carcinomas, neuro-endocrine carcinoma, apocrine carcinoma and acinic cell carcinoma. The tumors were designated as triple negative based on ER, $P R$, HER 2/neu staining. The proliferative index (Ki-67) and as well as AR staining were additional done, which showed $16.66 \%$ cases of AR positivity and most of which showed high proliferative index more than $21 \%$.
\end{abstract}

Keywords: TNBC, Androgen receptor, Breast carcinoma.

\section{Introduction}

Breast cancer is the second most common cancer in women which accounts for $23 \%$ of all female cancers, posing a major public health problem worldwide. The expression of $\mathrm{AR}$ in primary breast carcinoma is $60 \%-70 \%$ i.e. in infiltrating ductal carcinoma (IDC) non- basal type, ductal carcinoma in situ (DCIS), lobular carcinoma, BRCA positive cases and Paget's disease ${ }^{[1]}$. The expression of AR in ER negative tumour is $30 \%$, whereas the AR positivity in TNBC is $20 \%{ }^{[2-5]}$.
Triple negative breast cancer (TNBC) is defined as negative for ER, PR $(<1 \%$ of tumour cell nuclei) ${ }^{[8]}$ and Her2/neu (score of $0,1+$ or $2+$ ) comprising of high grade IDC, metaplastic carcinoma, medullary carcinoma, neuroendocrine carcinoma and apocrine carcinoma. TNBC occurrence is around $15 \%-20 \%$ of all breast cancers. This is not only a prognostic factor but also a predictive factor. Thus, it may reflect the natural history of tumour (prognostic factor) and the likely response to the treatment (predictive 
factor $)^{[2-3]}$. The AR positivity decreases in the endstaged metastatic disease showing an importance of AR targeted therapy at an earlier stage ${ }^{[2-5]}$.

\section{Materials and Methods}

The total number of cases of breast carcinoma included in the study from eastern Indian population admitted in IMS and SUM hospital were 110 between the period of June 2015 to September 2018. Majority i.e. $72.22 \%$ belonged to $50-60$ years of age followed by $27.78 \%$ belonged to $<50$ years of age. Lumpectomy or mastectomy was done. Following which IHC for ER, PR, Her2/neu, AR, CK 5/6, p63 and Ki-67 was performed.

Cell proliferation (Ki-67) was assessed by counting at least 500 tumor cell nuclei (depending upon the availability of tumor) and graded as low $(<11 \%)$, intermediate (11-20\%), and high (>21\%) [6].

IHC for CK 5/6 was done using antibodies D5/16 B4 for CK5/6 (Dako, Glostrup, Denmark) and if the staining was found in $>50 \%$ of tumor cells, it was interpreted as positive and if $<50 \%$ of tumor cells, it was interpreted as negative, as previously reported $^{[7]}$.

For the IHC staining for AR, antigen retrieval was performed as follows: five micron sections were deparaffinised and rehydrated to deionized water. They were heated in citrate buffer $(\mathrm{pH}$ 6.0) using an electric pressure cooker for three minutes at 1215 pounds per square inch (PSI) at approximately 120 degrees Celsius. They were then cooled for ten minutes prior to immunostaining. All slides were loaded onto an automated system (DAKO Autostainer plus, DAKO) and exposed to $3 \%$ hydrogen peroxide for 5 minutes, incubated with primary antibody for thirty minutes, with labelled polymer for thirty minutes, 3,3'-diaminobenzidine (DAB) as chromogen for five minutes, and then with hematoxylin as counterstain for five minutes. These incubations are performed at room temperature and between incubations, sections are washed with Tris-buffered saline (TBS). The gradation was done for the AR positive cases as low ( $<10 \%$ of the nuclei showing positivity), medium (about 10\% moderate positivity and high $>10 \%$ strong positivity)

All the cases were evaluated independently by two pathologists. The consensus results were recorded and the discordances were resolved by review and discussion.

\section{Results}

The 110 women ranged in age from 28-70 (median, mean) years at the time of diagnosis. The TNBC cases were 24 cases which included high grade IDC (NOS) i.e. 12 cases, medullary carcinoma. 3 cases, metaplastic carcinoma i.e. 4 cases, neuroendocrine carcinoma i.e. 2 cases, acinic cell carcinoma (1 case) and apocrine carcinoma ( 2 cases). The gradation was done for the AR positive cases as low $(<10 \%$ of the nuclei showing positivity), medium (about $10 \%$ of the nuclei) and high (>10\% of the nuclei) . Amongst these cases, high positivity AR status was found in post-menopausal age group (>50 years) and low positivity in pre and peri-menopausal age groups ( $<50$ years). Tumour size varied from $0.5 \mathrm{~cm}$ to 10 $\mathrm{cm}$. The maximum occurrence of AR positivity was seen in breast tumour of $<3 \mathrm{~cm}$ in size. The variants of tumours showing AR positivity were high grade IDC (NOS) [ $n=2,16 \%]$ (fig.1a \& 1b) and apocrine carcinoma $[\mathrm{n}=2,100 \%]$ (fig.2a \& 2b). The metaplastic carcinoma, medulary carcinoma, acinic cell carcinoma and neuroendocrine carcinoma were AR negative (fig.3 \& 4). One case of TNBC was found to be basal type showing strong CK5/6 positivity and was found to be AR negative. Strong AR positivity was found in $9 \%$ cases whereas, medium and low positivity was seen in 4 and $1 \%$ cases respectively (Fig 5). 


\section{JMSCR Vol||07||Issue ||01||Page 816-821||January

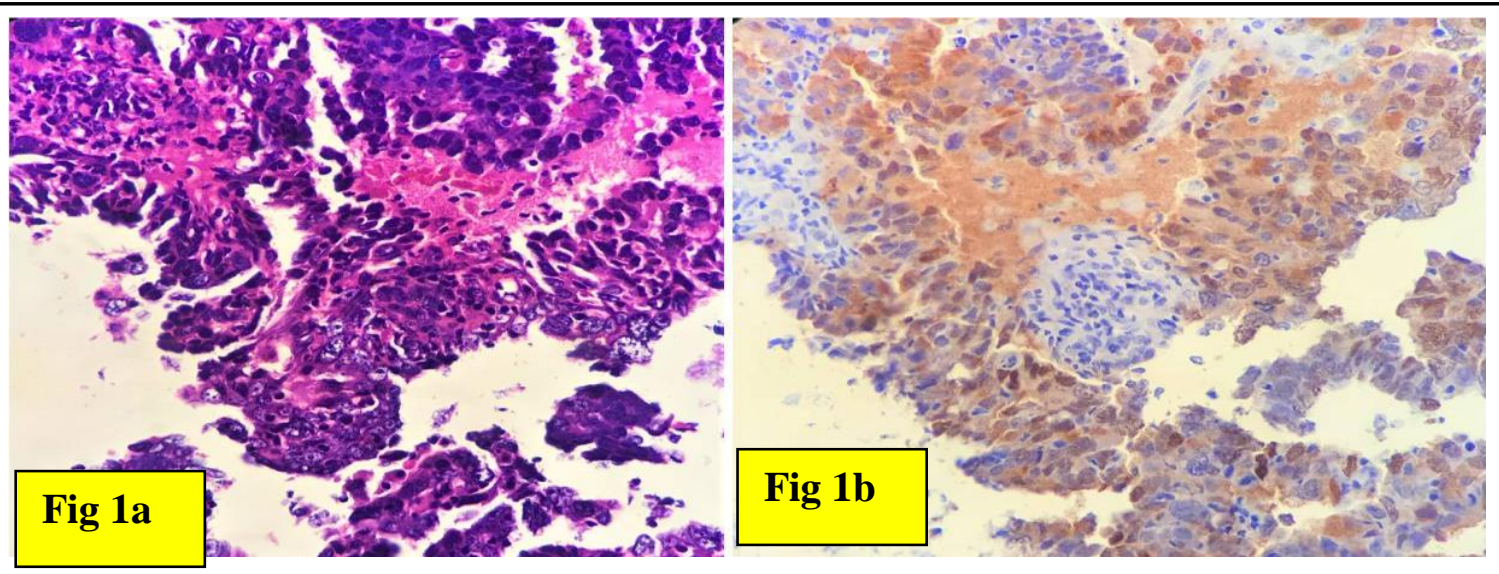

Fig 1a Microphotograph of IDC-NST (MBR grade III) showing neoplastic cells in papillae (H\&E x 400), 1b AR moderate positive (IHC X 400)
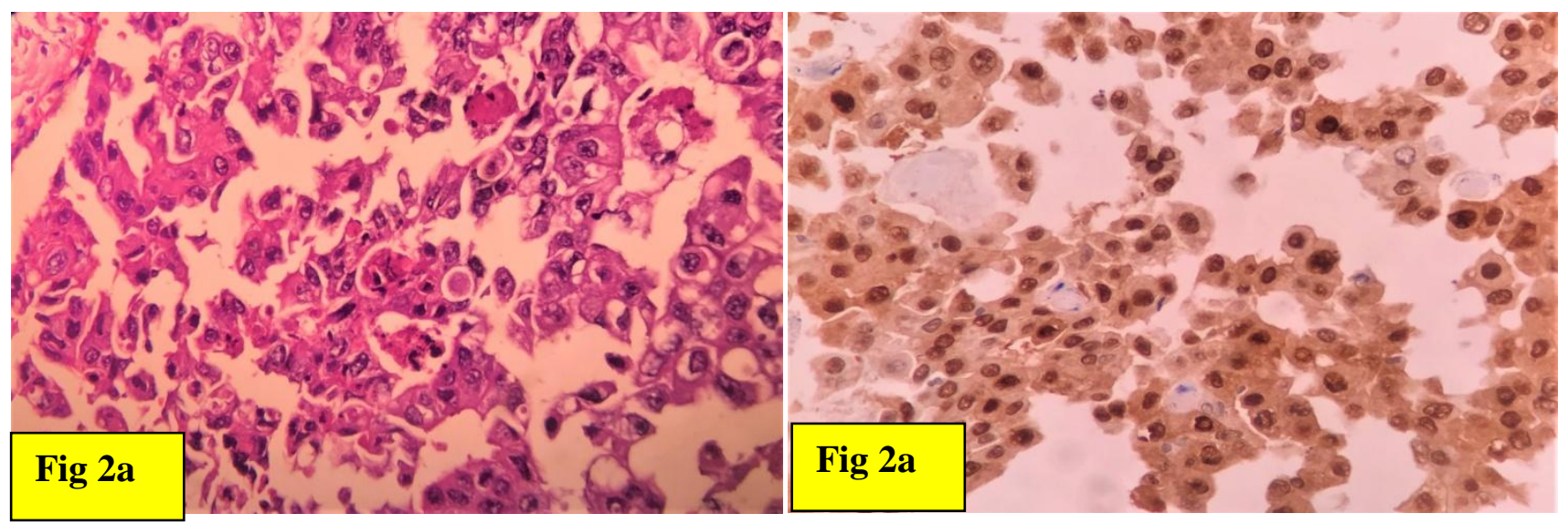

Fig 2a Microphotograph of apocrine carcinoma showing ductal epithelial cells showing apocrine change and luminal secretion (H \& E X400), Fig 2b Strong AR positivity. (IHC X 400)

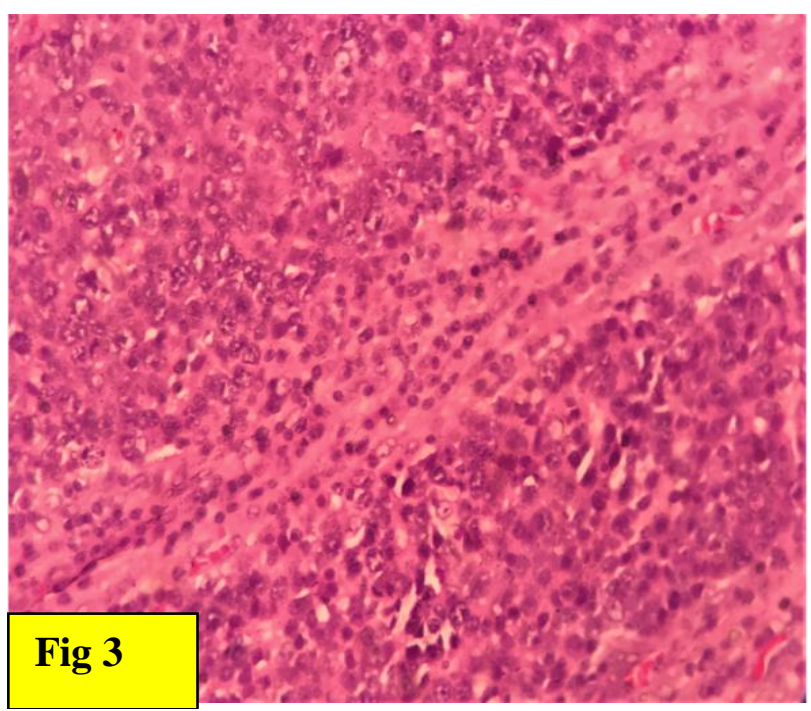

Fig 3 microphotograph of medullary carcinoma showing nests of neoplastic cells intervened by lymphocytes (H\& E X 400)

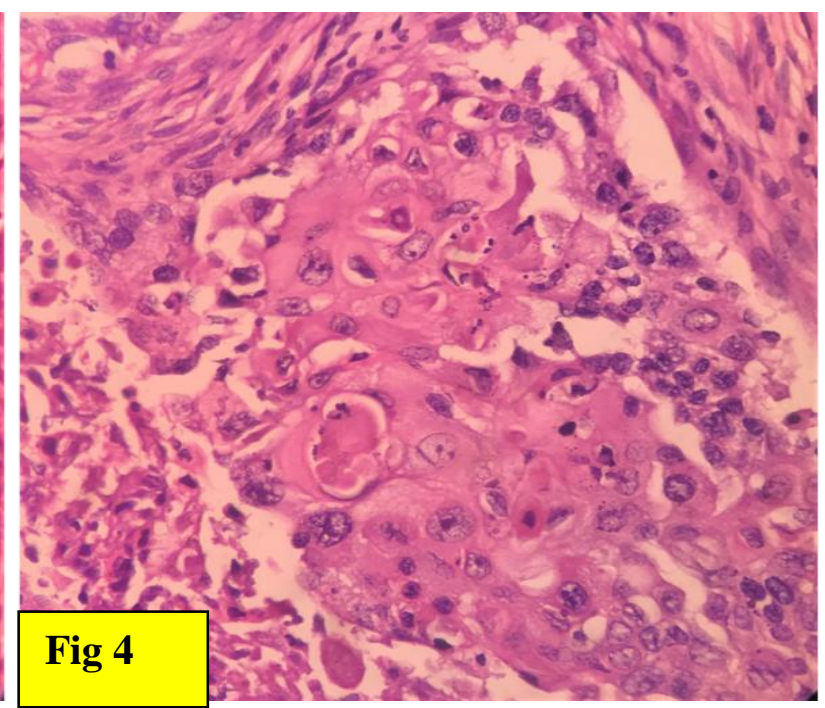

Fig 4 Microphotograph of Metaplastic (squamous) carcinoma of breast showing ductal cells with neoplastic squamous cells. (H \& E 400) 
Figure 5- Degree of AR positivity.

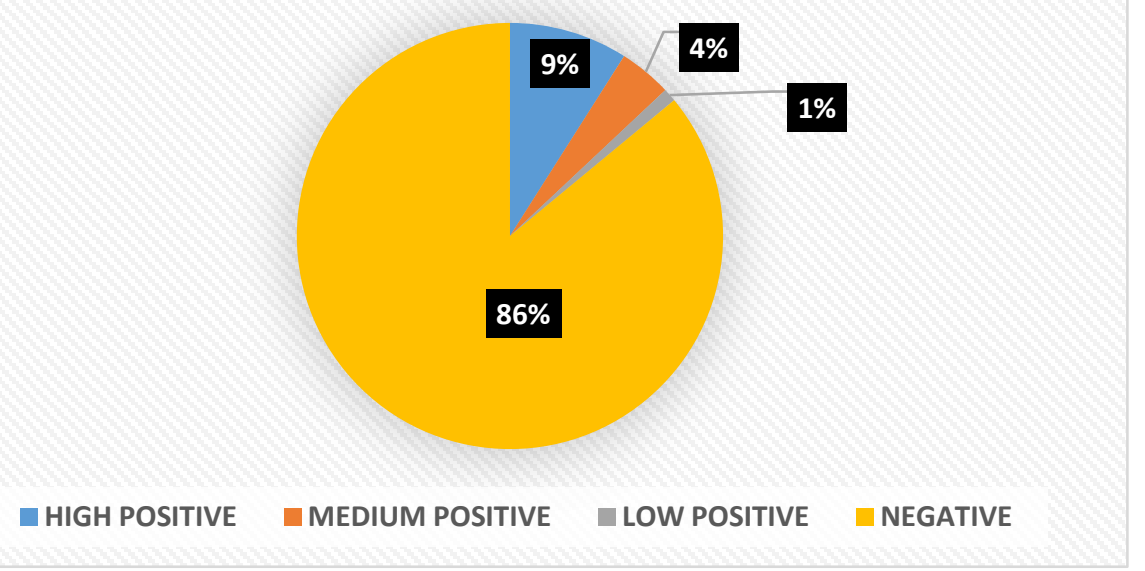

Fig 5

Positive AR status was found to be more associated with histologic grade III (75\%) tumours, whereas only one case of histologic grade II (25\%) showed moderate positivity. 13 out of 24 cases of TNBC showed metastasis to axillary lymphnode. In our study, maximum AR positivity was seen in 1-3 lymph nodes (75\%). Whereas 4-9 lymph node positivity was seen in $25 \%$ cases. AR positivity status was more commonly found in stage III cases. $83.33 \%$ of AR positive tumour showed high proliferative index (>21\%) (Table 1).

Table 1 Showing clinico-pathological correlation between AR positivity in various types of TNBC

\begin{tabular}{|c|c|c|c|}
\hline VARIABLES & $\begin{array}{c}\text { TOTAL TNBC } \\
\text { CASES }(\%)\end{array}$ & AR +VE CASES (\%) & $\begin{array}{c}\text { AR - VE CASES } \\
(\%)\end{array}$ \\
\hline TOTAL NUMBER OF PATIENTS (\%) & 24 & 4 & 20 \\
\hline \multicolumn{4}{|l|}{ AGE (YEARS) } \\
\hline$<50$ & 06 & 00 & 06 \\
\hline $50-70$ & 16 & 03 & 13 \\
\hline$>70$ & 02 & 01 & 01 \\
\hline \multicolumn{4}{|l|}{ TUMOUR SIZE } \\
\hline$<2 \mathrm{~cm}$ & 11 & 00 & 11 \\
\hline $2 \mathrm{~cm}-5 \mathrm{~cm}$ & 09 & 04 & 05 \\
\hline$>5 \mathrm{~cm}$ & 04 & 00 & 04 \\
\hline \multicolumn{4}{|l|}{ TYPES OF TUMOUR } \\
\hline 1. High grade IDC (non-basal like) & 10 & 02 & 10 \\
\hline 2. High grade IDC (basal type) & 02 & 00 & 00 \\
\hline 3. Apocrine CA & 02 & 02 & 00 \\
\hline 4. Medullary CA & 03 & 00 & 03 \\
\hline 5. Metaplastic CA & 04 & 00 & 04 \\
\hline 6. Neuroendocrine & 02 & 00 & 02 \\
\hline 7. Acinic cell CA & 01 & 00 & 01 \\
\hline \multicolumn{4}{|l|}{ GRADE } \\
\hline I & 02 & 00 & 02 \\
\hline II & 06 & 01 & 05 \\
\hline III & 16 & 03 & 13 \\
\hline \multicolumn{4}{|l|}{ LYMPH NODE } \\
\hline pNo & 10 & 00 & 10 \\
\hline $\mathrm{pN} 1(1-3)$ & 09 & 04 & 05 \\
\hline pN2(4-9) & 03 & 00 & 03 \\
\hline $\mathrm{pN} 3(10$ and $>)$ & 01 & 00 & 01 \\
\hline $\mathrm{pNx}$ & 01 & 00 & 01 \\
\hline \multicolumn{4}{|l|}{ STAGE } \\
\hline I & 00 & 00 & 00 \\
\hline II & 05 & 00 & 05 \\
\hline III & 16 & 04 & 12 \\
\hline IV & 03 & 00 & 03 \\
\hline NA & 00 & 00 & 00 \\
\hline \multicolumn{4}{|l|}{ Ki-67 } \\
\hline$\leq 10 \%$ & 01 & 00 & 01 \\
\hline $11 \%-21 \%$ & 03 & 00 & 03 \\
\hline$>21 \%$ & 20 & 04 & 16 \\
\hline
\end{tabular}




\section{Discussion}

Breast cancer cases with ER positivity is about 70 $\%$, HER 2 neu positivity is about $15 \%$ and TNBC is about $15 \%^{[9,10]}$. The occurrence of AR in TNBC has recently drawn attention. One third of ER negative cases and one third of BRCA positive cases with high grade invasive cancers have AR expression $^{[1,12]}$.

Androgens are necessary precursors of estrogen synthesis in the ovary. Androgens are secreted by both ovaries and adrenals. The main androgen is secreted as Androgen dehydro epiandrosterone sulfate and non-sulphated forms (DHEAS or DHEA respectively) inhibits growth of breast cancer. Androstendione is the other precursor of testosterone converting the low potency to high potency form, expressed in many cell types such as stromal breast cancer cells and epithelial cells $^{[13]}$. Studies have shown increased testosterone levels and low progesterone levels have increased risk for breast cancer ${ }^{[14]}$.

Androgen has been described as a potential tumor suppressor in ER-positive breast cancers with its anti-proliferative effect presumed to result from cross talk between steroid receptor signaling pathways ${ }^{[15]}$. However, studies investigating AR in TNBC have reported conflicting results. For example, Birell et al. noted that AR had a proliferative effect in ER and PR negative cell lines ${ }^{[16]}$ which was confirmed by Garay et al. and by Doanne et al., who raised the possibility of targeting the androgen pathway ${ }^{[17,18]}$.

AR positive TNBCs were found in $16.66 \%$ cases of TNBCs in our study, majority of which occured in post menopausal patients ( $>50$ year). The average tumor size was 2-5 centimetres. Luo et al found that AR was expressed in 28\% TNBC and correlated significantly with postmenopausal status. The common grading was grade III (modified Bloom Richardson grading) showing 13 lymphnode metastasis. Rakha et al. reported that AR positivity was associated with higher grade. The common tumor showing AR positivity were Apocrine carcinoma and High grade IDC-NST, non-basal type. The basa type of IDC-NST was found to be negative for AR receptor compatible with Bryan et al ${ }^{[4]}$.

\section{Conclusion}

AR-positive TNBC may represent a breast cancer subtype with unique features that may be amenable to treatment with alternative targeted therapies. The AR positive tumours are more prone for recurrance and metastasis. Such metastatic tumours usually yield AR negativity. Thus the target therapy at an early stage is extremely important in all cases of AR positive TNBCs.

\section{References}

1. Hardin C, Pommier R, Calhoun K, Muller P, Jackson T, et al. (2007) A new harmonal therapy for estrogen receptor negative breast cancer. World J Surg 31: 1041-1046

2. Park S, Koo JS, Kim MS, Park HS, Lee JS, et al. (2011) Androgen receptor expression is significantly associated with better outcomes in estrogen receptorpositive breast cancers. Annals of Oncology 22: 1755-1762.

3. Bryan RM, Mercer RJ, Bennett RC, Rennie GC, Lie TH, et al. (1984) Androgen receptors in breast cancer. Cancer 54: 2436-2440.

4. Trivers KF, Lund MJ, Porter PL, LiffElaine JM, Flagg W, et al (2009) The epidemiology of triple-negative breast cancer, including race. Cancer Causes Control 20: 1071-1082.

5. Lin NU, Vanderplas A, Hughes ME, Theriault RL, Edge SB, et al. (2012) Clinicopathologic features, patterns of recurrence, and survival among women with triple-negative breast cancer in the National Comprehensive Cancer Network. Cancer 118: 5463-5472.

6. Fitzgibbons PL, Page DL, Weaver D, Thor AD, Allred DC, Clark GM, et al. (2000) Prognostic Factors in Breast Cancer. 
College of American Pathologists Consensus Statement 1999. Arc Pathol Lab Med. 2000; 124 (7):966-978.

7. Rakha EA, El-Sayed ME, Green AR, Lee AH, Robertson JF, Ellis IO. Prognostic markers in triple-negative breast cancer. Cancer. 2007; 109:25-32. https://doi.org/10.1002/cncr.22381 PMID: 17146782

8. Wolff AC, Hammond EH, Schwartz JN, Hagerty KL, Allred DC, Cote RJ, et al. American Society of Clinical Oncology/ College of American Pathologists guideline recommendation for human epidermal growth factor receptor 2 testing in breast cancer. J Clin Oncol. 2007; 25:118-145 https://doi.org/10.1200/JCO. 2006.09.2775 PMID: 17159189

9. Lachapelle J, Foulkes WD (2011) Triple negative and basal like breast cancer implications for Oncologists. Curr Oncol 18: 161-164.

10. Hanley K, Wang J, Bourne P, Yang Q, Gao AC, et al. (2008) Lack of expression of AR may play a critical role in transformation from in situ to invasive basal subtype of high grade ductal carcinoma of breast. Hum Pathol 39: 38692.

11. Hanley K, Wang J, Bourne P, Yang Q, Gao AC, et al. (2008) Lack of expression of AR may play a critical role in transformation from in situ to invasive basal subtype of high grade ductal carcinoma of breast. Hum Pathol 39: 386392.

12. Pristauz G, Petru E, Stacher E, Geig JB, Schwarzbrau T, et al. (2010) Androgen receptor expression in breast cancer patients tested for BRCA 1and BRCA 2mutations. Histopathology 57: 877-884.
13. Secreto G, Toniolo P, Pisani P, Recchione C, Cavalleri A, et al. (1989) Androgens and breast cancer in premenopausal women. Cancer 49: 471-476.

14. Grattarola R (1964) The premenstrual endometrial pattern of women with breast cancer. A study of progestional activity. Cancer 17 : 1119-1122.

15. Hickey TE, Robinson JL, Carroll JS, and Tilley WD. Mini review: The androgen receptor in breast tissues: growth inhibitor, tumor suppressor, oncogene? Mol Endocrinol. 2012; 26(8):1252-1267. https:// doi.org/10.1210/me.2012-1107 PMID: 22745190.

16. Birell SN, Hall RE, Tilley WD. Role of the androgen receptor in human breast cancer. J Mammary Gland Biol Neoplasia. 1998; 3:95-103.

https://doi.org/10.1023/A:1018730519839 PMID: 10819508.

17. Garay JP, Karakas B, Abukhdeir AM, Cosgrove DP, Gustin JP, Higgins MJ, et al. The growth response to androgen receptor signaling in ER-negative human breast cells is dependent on p21 and mediated by MAPK activation. Breast Cancer Res. 2012; 9:14.

18. Doane AS, Danso M, Lal P, Donaton M, Zhang L, Hudis C, et al. An estrogen receptor negative breast cancer subset characterized by a hormonally regulated transcriptional program and response to androgen. Oncogene.2006; 25:3994-4008. https://doi.org/10.1038/sj.onc.1209415 PMID: 16491124. 